\title{
A América Latina e os Limites do Estado desenvolvimentista na Governança Neoliberal Global
}

Recebido: 31-03-2019

Aprovado: 25-06-2019

Ricardo de Castro Rebello

\section{Introdução}

Depois de sucessivos anos no poder, a esquerda latino-americana parece ainda atordoada com a escalada populista, referendada pelas urnas, de governos de direita nos principais países da região. Entretanto, este quadro de "retrocesso" das esquerdas ou do giro à direita do espectro político também reflete aspectos sistêmicos, de estruturas políticoepistêmicas $^{2}$ e do regime de governança neoliberal presentes na atual fase do "capitalismo regulatório" (BRAITHWAITE, 2005).

Desse modo, nossa principal premissa repousa sobre o entendimento da importância das estruturas político-epistêmico hegemônicas (globais) para a configuração e difusão do regime de governança neoliberal. Isto não significa minimizar o papel ou a relevância dos Estados (tampouco dos mercados internos), mas intenta, sobretudo, ressaltar suas interações com o contexto global. Por isso, vale destacar que o atual quadro de ascensão ao poder de partidos de direita está envolto na dinâmica de lutas político-ideológico hegemônicas implicadas na difusão de suas visões e modelos, que correspondem a seus respectivos interesses e perspectivas. Neste sentido, a análise das forças históricas que ajudaram a realimentar o viés político conservador (e a difusão de ideias, práticas e políticas econômicas

\footnotetext{
${ }^{1}$ *Doutor em Políticas Públicas (UERJ), orientado pelo então Secretário Executivo da CLACSO, Prof. Dr. Pablo Gentili; Mestre em Relações Internacionais (UnB); Especialista em Relações Internacionais (UnB); economista formado pelas Faculdades Cândido Mendes/RJ. Pesquisador no pós-doutorado do Laboratório de Pesquisa sobre Estado e Desenvolvimento nas Américas (Unb), coordenado pelo Prof. Dr. Moisés Balestro. Há mais de 18 anos atua como professor universitário em diversas instituições privadas de Brasília (IESB, UNICEUB, UNEB, entre outras). Consultor de projetos e programas de cooperação internacional (Banco Mundial, agências das Nações Unidas - PNUD e UNESCO, Secretaria de Assuntos Internacionais - SEAIN/MP, e Secretaria Executiva SE/MDIC). Correio eletrônico: ricardorebello1 @ hotmail.com

${ }^{2} \mathrm{O}$ termo "estruturas político-epistêmicas", é utilizado neste artigo para designar as relações entre agentes e estruturas de poder, e os mecanismos de produção e circulação de conhecimento na esfera das políticas/atividades das instituições multilaterais de desenvolvimento, de suas múltiplas imbricações na elaboração e aplicação de conceitos e práticas dos aparatos regulatórios da governança, e de suas implicações para a construção de perspectiva epistêmica positivista, de orientação tecnocrática e descontextualizada das realidades daqueles países a que se destinam.
} 
neoliberais) pode auxiliar na apreensão das estruturas normativo-epistêmicas que o sustentam. Caráter histórico que, segundo Woo-Cumings (1999: x) deve estar presente na análise do ambiente que envolve os diferentes padrões assumidos pela economia política do Estado desenvolvimentista: "Every political economy persists, changes, goes forward or backward, in some deeply complex, intimate, and consequential relationship to its own past".

Contudo, embora estas estruturas político-epistêmicas convencionalmente tendem a refletir os imperativos hegemônicos, respondendo aos interesses instrumentais e às agendas específicas de um grupo seleto de atores (nacionais e transnacionais), suas estratégias políticas também competem com alternativas visões e perspectivas políticas. Neste sentido, estas estruturas político-epistêmicas estão condicionadas, em maior ou menor medida, aos diferentes contextos políticos, econômicos, sociais e culturais (locais, nacionais e regionais) em que se inserem. É este instável equilíbrio entre legitimidade e efetividade que explica o caráter difuso e ambíguo do regime de governança global; características que, segundo Springer (2015), conferem maior adaptabilidade e durabilidade ao processo de neoliberalização ${ }^{3}$ nas sociedades contemporâneas.

Tendo em vista as precedentes observações, o recorte analítico proposto diferentemente do enfoque clássico da análise econômica e da teoria do crescimento econômico (alocação e distribuição de recursos) - procura evidenciar os efeitos condicionantes das ideias e instituições hegemônicas, e do regime de governança global ("background forces" - forças subjacentes) na formulação das políticas econômicas da América Latina, especificamente, o contexto epistemológico que subjaz a interação entre a manutenção do status quo político (conservador), das crenças e ideias (progressistas ou não) que moldam a economia política do desenvolvimento. Nesse sentido, nosso objetivo está alinhado com a natureza cognitiva, intersubjetiva e institucional da economia política e, por conseguinte, dos processos de elaboração e difusão de ideias e conceitos.

Seguindo por esta perspectiva construtivista, delimitamos nosso foco sobre aspectos relacionados à globalização neoliberal, aos regimes de regulação transnacionais (governança), e de suas interfaces e possíveis influências para a emergência (ou não) de alternativas político-econômicas, especificamente, o novo desenvolvimentismo latino-americano. Com

\footnotetext{
${ }^{3}$ De acordo com Brenner, Peck \& Theodore, o processo de "neoliberalização" enfatiza a natureza processual, relacional e variada de reestruturação regulatória e de constituição dos sujeitos. Brenner, N., Peck, J., and Theodore, N. (2010). Variegated Neoliberalization: Geographies, Modalities \& Pathways. Global Networks. 10,2 .
} 
efeito, as estruturas político-epistêmicas de governança não atuam de forma uniforme nos espaços sociopolíticos (e institucionais) locais, nacionais e regionais, tampouco estão isentas de contestação (onde se abrem portas às forças de emancipação) por parte de diferentes grupos e interesses em suas respectivas esferas de atuação política (formais e informais). Em outras palavras, a governança também configura uma arena política dinâmica, marcada por multifacetadas ideias, valores, visões de mundo, crenças e culturas (ideoscapes/ideopanoramas ${ }^{4}$ ), onde coabitam atores hegemônicos e contra hegemônicos (APPADURAI, 1990).

É sob esse ponto de vista político-epistêmico que este artigo intenta responder a duas indagações interligadas: Quais são os possíveis impactos do regime de governança neoliberal global sobre a América Latina? A partir de uma perspectiva crítica, aberta às progressivas forças sociais e políticas da América Latina, de que forma articular o posicionamento estratégico da região diante do aparato político-epistêmico da governança neoliberal global? Assim, embora estas indagações suscitem outras abordagens e temáticas para futuras pesquisas, nosso escopo de análise está referenciado e delimitado aos possíveis limites político-epistêmicos representados pelas forças neoliberais e do regime de governança global frente às ideias que conformam as bases teóricas do novo desenvolvimentismo na América Latina.

Iniciamos, portanto, por um breve recorrido que retrocede ao momento de crise/ruptura, que antecede o avanço da "onda neoliberal". No plano da economia política global, evidencia-se - já no começo da década de 70, com o fím da paridade de US\$35,00 por onça de ouro e a introdução do sistema de câmbio flutuante - o clímax das contradições no regime de acumulação capitalista (fordista); inflação e desemprego em alta nas principais economias mundiais (HALL, 1989). É o início progressivo do desmonte das políticas Keynesianas, dos choques do petróleo (1973 e 1979) e das subsequentes crises da dívida externa (México, Brasil, Argentina), das desregulamentações e dos programas de ajuste estruturais, e do avanço de um conjunto de ideias, prescrições, políticas e práticas governamentais neoliberais (décadas de 80 e 90); difundidas e mimetizadas por todo o globo. No plano ideacional, tais políticas vieram acompanhadas pela ascensão do discurso neoliberal de Reagan e Thatcher (There is no alternative - TINA) e pela messiânica tese do "Fim da

\footnotetext{
${ }^{4}$ Segundo Appadurai, ideopanoramas são: "elementos da visão de mundo Iluminista, que consiste em uma concatenação de idéias, termos e imagens, incluindo 'liberdade', 'bem-estar', 'direitos', 'soberania', 'representação' e o termo chave 'democracia'". (1990, p. 9-10).
}

Revista de Estudos e Pesquisas sobre as Américas V.13 N.2 2019 ISSN: 1984-1639 
História"

Não obstante o alcance e abrangência dessas transformações e de seus desdobramentos teóricos, conceituais e práticos para as ciências sociais, interessa-nos direcionar o foco deste artigo para o campo de estudo da economia política, notadamente, as interfaces da economia política do desenvolvimento com as análises institucionais. Sobretudo, recortar a análise à dimensão epistêmica do regime de governança global e do contexto político referenciado pela guinada à direita dos principais governos da região, e de seus possíveis efeitos para o debate do novo papel do Estado no desenvolvimento nacional: o que se convencionou denominar "social-desenvolvimentismo" ou o "novo desenvolvimentismo" latino-americano.

Então, de modo a ressaltar os aspectos político-normativo-epistemológicos que moldam as estratégias político-econômicas na atual fase de ascensão dos governos de direitas, as opções se fecharam em torno do receituário econômico neoliberal. Tanto o partido republicano dos Estados Unidos, quanto boa parte dos partidos de direita no continente europeu (ressalva-se, nestes dois casos, a polissemia do conceito de direita) irmanam-se no desmonte das ideias, práticas e políticas adotadas pelos partidos de esquerda nos últimos anos. Então, pode-se dizer que o pêndulo político-epistemológico e as agendas econômicas mundiais assumem posição à direita do espectro político. Com isso, ressurgem, com vigor antes inimaginável, versões radicais de nacionalismo político, isolacionismo econômico e xenofobia. Rupturas que, se tomadas em seu conjunto, sinalizam para um novo arranjo institucional e ideológico da ordem internacional (pós-Westphalia) ou, para os mais céticos, o retorno à organização social e política medieval (novo medievalismo) ${ }^{6}$.

Todavia, não seria prudente concentrar a análise apenas em aspectos conjunturais, relacionados às recorrentes idas e vindas das dinâmicas políticas e das estratégias de acumulação de capital em diferentes países ou regiões - dos cenários políticos domésticos (KINGSTONE, 2011) - mesmo que estes atores representem o "clube" de potências econômicas mundiais. Desse modo, nossa análise prioriza o caráter institucional, os processos macro-políticos do sistema de governança (global) neoliberal, e as ideias que os formatam, com suas possíveis implicações para a economia política regional e o desenvolvimento latinoamericano. Com efeito, nosso foco ressalta a lógica institucional (estrutural) da base político-

\footnotetext{
${ }^{5}$ FUKUYAMA, Francis. O fim da história e o último homem. Rio de Janeiro: Rocco, 1992. Seu principal e simplista argumento refere-se à queda do Muro de Berlim (dissolução do mundo bipolar) - 1989 -, como o evento que marca o "fim da história"; a derradeira e inexorável vitória do livre-mercado e da democracia liberal. 6 BULL, Hedley 2nd Ed.(1995). The Anarchical Society: A Study of Order in World Politics. Houndmills, Macmillan.
}

Revista de Estudos e Pesquisas sobre as Américas V.13 N.2 2019 ISSN: 1984-1639 
epistêmico neoliberal, identificada como o palco político do instável balanço de forças centrífugas e centrípetas do regime de governança global, onde distintos atores (estatais e não estatais) e assimétricas capacidades de manobra forjam o futuro cenário do desenvolvimento da América Latina.

Assim, partimos do pressuposto de que a emergência da dimensão transnacional atores, ideologias, valores e modos de organização sociais atuantes fora de seus respectivos espaços nacionais - engendra o amálgama de crenças, representações e discursos políticos, no qual se expressam movimentos dinâmicos e voláteis de interesses e redes de ideias em constante e mútua constituição. Em outras palavras, destacamos que nem sempre os motores de mudança (institucional e ideológica) das sociedades correspondem ao espaço físico das nacionalidades ou do abstrato conceito de soberania nacional, embora este "campo de batalha" assuma, cada vez mais, as características de um contexto socioeconômico global marcado por desiguais capacidades e forças epistêmicas, no qual prevalece a organização e difusão de ideias, práticas e valores dominantes, consubstanciados pelo conceito de governança (neoliberal) global.

Neste sentido, ao adotar abordagem que celebra a importância de aspectos institucionais e ideacionais - que precedem e forjam os interesses, modelando e guiando as decisões políticas (CAMPBELL, 1998; JOHN, 1998) -, este artigo intenta destacar o caráter normativo-epistêmico do regime de governança e de regulação transnacional para a construção das agendas e políticas domésticas. Tendo em vista estes aspectos sistêmicos, partimos da hipótese de que os caminhos (ou descaminhos) do desenvolvimento na América Latina estão vinculados à apreensão da dinâmica dos processos de institucionalização e normatização de estruturas político-epistêmico, conformadas segundo um conjunto de ideias e princípios, regras e normas, que pautam as políticas, as práticas e as "soluções” globais.

\section{Aspectos sistêmicos, governança neoliberal e o cenário da crise política global}

As últimas décadas foram marcadas por recorrentes e sistêmicas crises econômicas mundiais. A crise do peso mexicano, de 1994-95, a crise financeira do Brasil, de 1999, o colapso dos mercados de ações dos EUA, de 2000, a crise das subprimes, de 2007/8, ilustram os efeitos perversos e o potencial desestabilizador dessas crises sobre as economias nacionais (em especial, nos países menos desenvolvidos, como os latino-americanos), e que também contribuem para a reconfiguração sistêmica das formas de regulação da acumulação 
capitalista global. Contudo, não obstante a avalanche de reações sociais e protestos políticos suscitados por manifestações multitudinárias antiglobalização (Fórum Social Mundial, em 2001; primavera árabe, em 2011; Seattle, em 1999; Praga, 2000, Buenos Aires, 2001, Gênova, 2001, Quebec, em 2003 etc.), as tradicionais formas de representação política, as instituições e as práticas neoliberais parecem adquirir maior ímpeto e resiliência ${ }^{7}$.

Com efeito, a despeito da crescente aversão dos cidadãos e cidadãs aos partidos e à representação democrática, aos programas e ideologias de controle centralizado do Estado carreado por estas manifestações sociais e políticas (Estados Unidos, Canadá, Islândia, Egito, Tunísia, Grécia, França, Itália, Portugal, Brasil, Espanha, Turquia etc.), estudos políticos recentes (DRAKE, 2006) destacam que os discursos e as práticas neoliberais se revitalizaram ${ }^{8}$ no pós-crise 2007/8. Não obstante os inequívocos sinais da insatisfação popular, a lógica econômica neoliberal ou a capacidade de resiliência política do sistema se manteve relativamente estável, mesmo após o turbilhão de falências de grandes seguradoras, fundos de pensão, fundos de investimentos ("hedge funds") e, sobretudo, os devastadores impactos sobre as principais corporações financeiras estadunidenses e europeias. Sob a recorrente retórica neoliberal - "too big to fail", a solução ensejada pelos órgãos de controle estatais para a manutenção do sistema: a injeção de massivos aportes de recursos públicos. De modo que as agendas políticas e econômicas ortodoxas (neoliberais) reaparecem, tanto no âmbito das estratégias políticas domésticas, assim como no desenho dos projetos e programas de ajuda ao desenvolvimento: marketização de serviços públicos (educação, saúde, etc.), privatizações, concessão de bens públicos à exploração privada; o que, no jargão econômico, se denomina "business as usual". Estas são estratégias que corroboram a conhecida "receita neoliberal" de utilização de instrumentos de gestão e controle dos gastos sociais, e do retorno das políticas de austeridade, que integram, indistintamente, as agendas político-econômicas de países ricos, pobres e emergentes.

Por outro lado, na América Latina, apesar das expectativas geradas - sobretudo na esfera social, no combate à pobreza e à desigualdade -, a tomada do poder dos partidos de esquerda (Brasil, Argentina, Uruguai, Chile, Venezuela, Bolívia, Equador; apenas para citar

\footnotetext{
${ }^{7}$ Nas ciências sociais, especificamente no campo da economia política do desenvolvimento, o termo resiliência vem associado ao "ethos do empreendedor", de responsabilidade (individual e coletiva), de adaptação às mudanças; da volatilidade do entorno sociopolítico e econômico neoliberal.

${ }^{8}$ As políticas neoliberais das principais economias mundiais - EUA e países da União Europeia - são forçadas ao interlúdio (socorro financeiro e massivas intervenções estatais na economia) durante a fase mais aguda da crise financeira de 2007/8.
} 
alguns países) não lograram de forma efetiva romper as amarras das ideias e prescrições impostas pelo modelo hegemônico neoliberal. De fato, as últimas eleições nos principais países latino-americanos demonstram a frágil base política dos partidos de esquerda frente aos atávicos interesses de elites conservadoras (associadas aos capitais externos - produtivos e financeiros) pela manutenção do status quo de importantes setores econômicos - públicos e privados: sob esse ponto de vista, a luta de classes e o materialismo econômico de Marx sobrevivem em pleno século XXI.

Desse modo, já no início da segunda década do novo milênio, a balança política pendeu novamente para a direita; o que significou o reforço às políticas econômicas neoliberais - Argentina (Macri), Brasil (Temer/Bolsonaro) e Chile (Piñera). O efeito dominó do fracasso eleitoral das esquerdas latino-americanas implicou na diminuição do papel central do Estado e de sua função regulatória e compensatória nas esferas sociais e econômicas. Os avanços sociais alcançados pelos regimes de esquerda logo se desfizeram, aprofundando o fosso de desigualdade, precarização social e atraso econômico na região. No palco das políticas externas, o que parecia ser uma nova forma de inserção internacional, autônoma, direcionada para parcerias regionais e de cooperação sul-sul - baseada na ampliação do protagonismo político-estratégico da região (principalmente do Brasil - com o BRICS Brasil, Rússia, Índia, China e África do Sul), perde densidade frente ao descaso para com o regionalismo latino americano e ao subsequente alinhamento automático dos principais governos de direita da região com os Estados Unidos.

No entanto, durante o período dos governos de esquerda, também surgem na região renovadas iniciativas analíticas centradas na busca por alternativas políticas capazes de romper com a dependência externa: um "consenso" que paulatinamente se articula com o objetivo de promover o desenvolvimento econômico, a democracia, a diversidade cultural e a igualdade de oportunidades. Partindo da experiência de muitos países do leste asiático (Japão, Coreia do Sul, Taiwan, China, Singapura etc.) que lograram reverter o atraso econômico, promovendo a inclusão social e o desenvolvimento produtivo-tecnológico (JOHNSON, 1987; AMSDEN, 1989; HAGGARD, 2004), os principais governos de esquerda latino-americanos, fortalecidos pelo apoio popular e um cenário econômico externo favorável - boom dos preços das commodities -, começam a vislumbrar alternativas ao "Consenso de Washington" e as prescrições neoliberais nele contido.

De fato, o Estado desenvolvimentista pode ser entendido como um conjunto de ideias 
e perspectivas que atribui papel protagônico ao Estado no planejamento, direção e coordenação do processo político, social e econômico para o desenvolvimento nacional. Com efeito, o Estado desenvolvimentista apresenta-se como reação e busca de alternativas políticas progressistas diante dos baixos índices de crescimento, do aumento da desigualdade e das tensões sociais durante os 20 anos (depois da crise da dívida externa e dos programas de ajuste estruturais, de 1982) de hegemonia das políticas e discursos neoliberais promovidas na região por organismos internacionais (Banco Mundial - BIRD, Fundo Monetário Internacional - FMI e Organização Mundial do Comércio - OMC). Vale também destacar que, assim como ocorreu no leste asiático, o novo desenvolvimentismo latino-americano promoveu o avanço de estratégias coordenadas de integração regional ${ }^{9}$ e de contestação da influência norte-americana na região. Foi neste contexto político de ascensão e aglutinação das esquerdas latino-americanas que se consolidou o denominado novo desenvolvimentismo.

\section{O giro institucional e o novo desenvolvimentismo}

Convencionalmente, as ciências sociais (desde a economia neoclássica até as versões mais funcionalistas do marxismo) tratam de aspectos estruturais, - socioeconômicos e políticos-culturais -, a partir da visão funcionalista/liberal, a partir do modelo realista de atores racionais, inseridos em contextos de interdependência funcional (MEYER, 1999). Tradição funcionalista intrinsecamente relacionada à mítica separação analítica entre Estado-sociedade, Estado-economia, às ideologias de progresso, e, mais recentemente, à noção de "governança global”. De maneira que a perspectiva funcional reserva às instituições (e aos sistemas sociais) papel meramente acessório, ou seja, as identificando como epifenômeno, dependente dos interesses e motivações de atores individuais e/ou coletivos racionais que buscam satisfazer seus propósitos ${ }^{10}$.

As primeiras versões do institucionalismo econômico ${ }^{11}$ (NORTH \& THOMAS, 1973)

\footnotetext{
${ }^{9}$ A Comunidade de Estados Latino-americanos e Caribenhos (CELAC), a Aliança Bolivariana para os Povos de nossa América (ALBA) e a União de Nações Sul-Americanas (UNASUL); esta última, em 2019, substituída pelo Fórum para o Progresso da América do Sul (PROSUL) - destaca-se a sintomática exclusão da Venezuela.

${ }^{10}$ Esta visão também é compartida pela versão mais radical da tese da globalização, que destaca a convergência e difusão político-institucional neoliberal e, com isso, a consolidação progressiva da lógica de mercado em todos os domínios econômicos e sociais.

11 Refiro-me às primeiras versões (de meados do século XX) do institucionalismo econômico, da "Nova Economia Institucional”, já que em sua fase mais madura, North destacará aspectos formais e informais que estruturam e organizam as interações sociais e econômicas. De todo modo, as instituições (as regras do jogo "the rules of the game") serão equacionadas aos possíveis desenhos institucionais mais adequados à redução da incerteza em fazer negócios (informação) e dos custos de transação.
}

Revista de Estudos e Pesquisas sobre as Américas V.13 N.2 2019 ISSN: 1984-1639 
são as que melhor retratam tais tendências funcionalistas. Elaboradas a partir de formulações da economia neoclássica, a chamada "Nova Economia Institucional" é baseada em parâmetros de eficiência que atentam para o caráter evolutivo das instituições e da organização dos sistemas sociais, e da predicabilidade das ações individuais e coletivas. Neste sentido, o institucionalismo econômico confere papel destacado aos incentivos econômicos ("get the prices right"), à busca pela eficiência dos desenhos institucional, assim condicionando o comportamento individual e coletivo às sinalizações de mercado (Homo economicus) e aos efeitos automáticos - "virtuosos" -dos fluxos de capitais para os países menos desenvolvidos (rendimentos decrescentes do capital); instituições que se apoiam em uma simples e determinística lógica econômica, baseada no sistema de preços, na relação custo-benefício, nas leis de concorrência, e nos direitos de propriedade privada; apenas para citar as mais importantes.

Embora os institucionalistas econômicos aportem a importante contribuição do impacto dos custos de transação das firmas (COASE, 1937) para a elaboração e análise de antigos e novos conceitos como externalidades, informações assimétricas e imperfeitas, bens públicos e bens privados ("free-rider") e, de forma geral, dos múltiplos equilíbrios assumidos pelas forças de mercado, pelas instituições, pelas ideias e pelas ideologias que moldam o funcionamento das sociedades e economias - "get the institutions right" -, sua lógica central é ainda tributária das origens funcionalistas e instrumentais da economia neoclássica. Desse modo, também vale ressaltar a advertência de Evans (2007) ao "giro institucional" na análise da nova economia institucional de North:

\begin{abstract}
"La versión de North del institucionalismo histórico, como la nueva teoría del crecimiento, sigue siendo convencional en un importante aspecto: el crecimiento del ingreso, estimado mediante índices de mercado, continúa siendo la medida fundamental del desarrollo. A pesar de las generosas declaraciones acerca de la importancia de otros fines sociales y políticos, estos últimos siguen siendo secundarios, e implícitamente se subordinan a la medida fundamental del ingreso. El pleno florecimiento del giro institucional depende de poder escapar de esta visión restrictiva". 12
\end{abstract}

Entretanto, já por volta das décadas de 1960/70, as ciências sociais se confrontam, por várias razões e evidências (BERGER \& LUCKMANN, 1967; BLUMER, 1969; GIDDENS, 1971) com as falácias das perspectivas funcionalistas, com os fracassos das políticas de desenvolvimento, com as lacunas do comportamento racional de atores e organizações, com

\footnotetext{
${ }^{12}$ Evans, Peter (2007). Los retos del "giro institucional", em Instituciones y Desarrollo em la Era de la Globalización Neoliberal. p. 194. Publicaciones ILSA. Bogotá, Colombia.
}

Revista de Estudos e Pesquisas sobre as Américas V.13 N.2 2019 ISSN: 1984-1639 
as incongruências entre o planejamento, as políticas formais e a realidade das práticas e das estruturas informais. Neste novo contexto, a literatura política e acadêmica intensifica o debate acerca das frágeis e instáveis fundações do princípio da racionalidade e das relações causa-efeito, tão caras aos funcionalistas. A partir dessas críticas, são impulsionadas análises institucionais que incorporam importantes variáveis e nuanças como: a racionalidade limitada - "bounded rationality" - (SIMON, 1983), a autonomia inserida (EVANS, 1995), a complexa interdependência (KEOHANE, 1977), assim como a análise dos efeitos de modulagem institucional sobre o comportamento de diferentes atores (nacionais e supranacionais): os Estados e as burocracias estatais, os empresários, as organizações intergovernamentais e não governamentais, e distintas representações sociais, indivíduos e coletividades. Esta guinada/retorno ${ }^{13}$ às instituições ("institutional turn") atinge vários outros campos das ciências sociais, como: as ciências políticas, a sociologia econômica, os estudos do desenvolvimento, a geografia econômica, a nova economia institucional e a economia política do desenvolvimento ${ }^{14}$.

Da mesma forma, em reflexões acerca do giro institucional na economia política comparada, Ebenau, Bruff \& May (2015) atribuem ao legado funcionalista à "primeira geração" da abordagem das variedades de capitalismo, destacando a herança da economia neoclássica. Tais tendências funcionalistas, embora ainda presentes no estudo das instituições, paulatinamente perdem força diante de suas próprias insuficiências explicativas e preditivas. Pois, segundo Gill (2015), o estudo de atores e práticas políticas, muitas vezes, tende a exacerbar, implícita ou explicitamente, as articulações institucionais de poder (ou de constelação de poderes) constituintes da manutenção do status quo global (instituições globais do poder neoliberal), ou seja, do locus hegemônico de articulação de interesses, dos modos de regulação e de difusão dos aparatos institucionais e discursivos que sustentam e conferem, em maior ou menor medida, legitimidade às estratégias políticas, epistêmicas e econômicas.

Por outro lado, o advento da "segunda geração" da economia política comparada (STREECK, 2012) implicará na ampliação e refinamento do escopo de análise (para além dos principais países e variedades de capitalismo). Destacam-se, então, os contextos institucionais e culturais, as práticas inseridas (practical embeddedness) e as especificidades dos sistemas

\footnotetext{
${ }^{13}$ Retorno, se considerarmos o legado do pensamento institucionalista (Veblen, Commons e Mitchell).

${ }^{14}$ Para uma visão mais atualizada, ver: Chang, Ha-Joon and Peter Evans. "The Role of Institutions in Economic Change”, in Gary Dymski and Silvana de Paula (eds), Reimagining Growth: Institutions, Development, and Society, pp. 99-140. London and New York: Zed Books. 2005.
}

Revista de Estudos e Pesquisas sobre as Américas V.13 N.2 2019 ISSN: 1984-1639 
capitalistas, assim como as dinâmicas interativas entre instituições e organizações, as múltiplas relações formais e informais entre o Estado e o mercado, entre governados e governantes, entre seguidores e formuladores de regras, assim como, das ideias, instituições, e atores de (re)produção de diversidade dos sistemas capitalistas (ESPING-ANDERSEN, 1990).

De forma que a crença em um Estado autônomo, desvinculado das pressões e influências externas, parece mais um recurso simplificador e mistificador, diante do emaranhado de relações/forças (sociais, políticas, culturais e econômicas) da realidade contemporânea. Com efeito, embora o "nacionalismo metodológico" ainda corresponda à referência principal das análises sociológicas (TAYLOR, 1996) e das principais correntes da economia política comparada e da análise institucional comparativa, segundo Schneider $(2013)^{15}$, as formas híbridas assumidas pelo capitalismo latino-americano e de outras regiões (Economias Hierárquicas de Mercado - EHM) - não se restringem aos tipos-ideais ou às categorias "clássicas" utilizadas pela perspectiva das variedades de capitalismo (Economias Liberais de Mercado - ELM, países de tradição anglo-saxão; e Economias Coordenadas de Mercado - ECM, países da Europa continental, Escandinávia, assim como, o Japão). Destacase que, nestas formas híbridas de capitalismo, as usuais premissas da economia neoclássica (por exemplo, o modelo mecânico de equilíbrio de mercado, o individualismo metodológico do comportamento racional, e o determinismo da ideia das preferências de atores individuais e coletivos) são refutadas, em favor de um quadro mais complexo baseado em processos dinâmicos de interação e mútua constituição de estruturas institucionais, cognitivas, valores e atores (HODGSON et al. 1994).

\section{Conclusão: O regime de governança global (neoliberal) e os limites do novo desenvolvimentismo}

Embora as ideias e políticas de desenvolvimento remontem às primeiras análises mercantilistas, das atividades dos fisiocratas franceses, das elaborações teóricas de Friedrich List, Adam Smith, Karl Marx, Albert Hirschman, Paul Baran, Gunnar Myrdal, Walt Rostow, Alexander Gerschenkron, entre tantos outros estudiosos, é comum se verificar calorosos debates e controvérsias políticas. Dentre essas principais controvérsias, Rist (2008) questiona

\footnotetext{
${ }^{15}$ Schneider, B.R. (2013) Hierarchical Capitalism in Latin America: Business, Labor, and the Challenges of Equitable Development (Cambridge: Cambridge University Press).
}

Revista de Estudos e Pesquisas sobre as Américas V.13 N.2 2019 ISSN: 1984-1639 
- a partir de análise histórica dos discursos políticos que perfazem as diferentes elaborações teóricas do desenvolvimento - a utilização do referencial teórico e das prescrições políticas hegemônicas como modelo a ser seguido por países atrasados ou menos desenvolvidos. Como um campo de estudo interdisciplinar e eminentemente afeito às paixões políticas, o desenvolvimento, sobretudo a partir do fim da II Guerra Mundial, é pródigo em modismos e humores instáveis. Assim, pode-se atribuir os "altos e baixos" de determinado modelo ou estratégia de desenvolvimento por sua consistência às realidades históricas, econômicas, sociais e culturais, por suas capacidades preditivas, legitimidade política e credibilidade social.

O próprio conceito de desenvolvimento, como impulso inerente à condição humana, base da estrutura epistêmica de formação do ethos da modernidade ocidental e das aspirações individuais e coletivas contidas nos ideais do iluminismo, passa por importantes reformulações teóricas no século XX. Não apenas se relativiza seus objetivos imediatos (econômicos, políticos e sociais), adicionando-lhes princípios éticos (direitos humanos e ambientais, questões de gênero, de raça, de religião; apenas para citar alguns), mas, também, se questionam as estruturas institucionais e epistêmico-normativas - eurocêntricas - sob as quais as "regras do jogo" são estabelecidas e solidificadas em desfavor dos que ainda não lograram posições mais favoráveis na "escalada" do desenvolvimento ou, em termos mais estritos, da acumulação de capital (CHANG, 2002).

Como sugere Willis (2005), esta longa trajetória histórica de reflexão teórica e prática acerca das políticas de desenvolvimento, embora imbricada em múltiplos contextos sociopolíticos, econômicos e culturais, esta delimitada às perspectivas epistêmicas, à produção de conhecimento gerado e gestado em centros especializados hegemônicos ("think tanks", organizações internacionais, universidades, e elites econômicas e políticas mundiais). Portanto, mais do que pressupor os múltiplos e peculiares processos de construção institucional dos distintos modelos (variedades) de capitalismo, ao contrário, advogamos pela necessidade de partir dos impactos da disciplina do regime de governança global (pela disciplina do capital, dominada pelas finanças, pelo individualismo e o risco; da estrutura epistêmica global hegemônica) sobre os diferentes contextos locais, nacionais e regionais (AGLIETTA, 1998). Desse modo, como explicar a resiliência de suas ideias e prescrições frente a seus evidentes fracassos e promessas não cumpridas? Uma das possíveis explicações pode ser atribuída ao caráter insidioso e difuso, pelas quais as estruturas epistêmicas e o 
discurso da governança neoliberal global incorporam diferentes (muitas vezes, divergentes) matizes políticos-ideológicos.

Recentemente, o centro das polêmicas sobre as políticas de desenvolvimento associase ao debate das capacidades individuais e estatais (SEN, 1999), da organização de estruturas políticas e de desenhos institucionais mais adequados para a promoção do desenvolvimento econômico e social. No entanto, podemos afirmar que há convergências - pelo menos nas linhas gerais dos discursos - entre os dois extremos desse debate. De modo que os principais representantes do status quo global (países ricos e organizações internacionais de cooperação ao desenvolvimento) coalescem com a relativização da ortodoxia econômica neoliberal, em prol da maior participação do Estado na economia e de seu papel mitigador das imperfeições de mercado. De maneira análoga, do lado dos países pobres e em desenvolvimento, reaparecem as ideias de um Estado forte e centralizador das decisões estratégias, de formação de consenso entre burocracia estatal e empresariado na condução do processo de desenvolvimento nacional. Vale aqui ressaltar o argumento de Leftwich:

"Only effective states and preferably developmental ones - whether democratic or not - are
capable of elaborating the institutions which will establish poverty reducing growth and
$\begin{array}{llll}\text { associated } & \text { welfare } & \text { regimes" } & \text { (LEFTWICH, }\end{array}{ }^{16}$

O novo desenvolvimentismo se insere dentro desse contexto, apresentando-se como um esforço teórico de superação dos constrangimentos internos e externos que condicionam a capacidade das economias menos desenvolvidas em alçar seus próprios voos rumo à construção de sociedades mais prósperas e justas. Embora urgido dentro de uma perspectiva contestatória de vigência dos partidos de esquerda na América Latina, há que se destacar até que ponto o novo desenvolvimentismo representa uma ruptura epistêmica ou, de outra forma, apenas limita-se a um processo de rearranjo (falacioso) da produção de conhecimento hegemônico, que visa a cooptação ou sedução - dos interesses políticos e motivações das elites econômicas e da nova direita latino-americana - à lógica da acumulação capitalista e aos interesses dos grandes capitais financeiros transnacionais.

Por outro lado, para que o novo desenvolvimento se constitua em efetiva alternativa aos modelos de desenvolvimento testados ou seguidos pelos principais países da região nas últimas décadas, é importante que não perca de vista os condicionantes sistêmicos de

\footnotetext{
${ }^{16}$ Apenas Estados efetivos e preferencialmente aqueles desenvolvimentistas - se democráticos ou não - são capazes de construir instituições que poderão estabelecer políticas associadas à redução de pobreza e aos regimes de bem-estar. (tradução própria)
}

Revista de Estudos e Pesquisas sobre as Américas V.13 N.2 2019 ISSN: 1984-1639 
regulação (os mecanismos de governança neoliberal global). Refiro-me ao caráter normativoprescritivo das "soluções" engendradas em organismos internacionais de cooperação internacional e do instrumentalismo econômico de seus modelos de desenvolvimento (Consenso de Washington e sua mais recente repaginação, o Pós-consenso de Washington). Este reduzido espaço de manobra, delimitado pela "camisa de força" da governança global ou das "inevitabilidades" da globalização - limiar entre a participação autônoma e a legitimidade política na esfera de atuação dos Estados na ordem internacional - o que James Petras (2003:2) designa como "novas formas de imperialismo" -, implica na capacidade de incorporar, adaptar e aprender com as experiências passadas (nacional-desenvolvimentismo dos anos 1960 e 1970), e das demais experiências históricas de sucesso do Estado desenvolvimentista (p.ex. Japão, Taiwan, Coréia de Sul, para citar apenas alguns países). Contudo, é importante ressaltar ainda os desafios dos estrangulamentos internos que dificultam a capacidade dos Estados, sobretudo aqueles mais endividados, onde o custo de capital é maior - comparativamente com China, Japão e Coreia do Norte - e incompatível com taxas de investimento (públicas e privadas) necessárias para impulsionar os índices de produtividade e de inovação. Por fim, em um ambiente político polarizado (doméstico e externo), marcado pelas crises econômicas e sociais, a busca por alternativas políticas e modelos de desenvolvimento, está associada ao desafio de construção de consensos sociais estratégicos (burocracias estatais, empresas e sociedade civil), de construção de instituições, capazes de conferir credibilidade e legitimidade às novas formas de produção de conhecimento; estes são os enormes desafios que se apresentam aos governos, à academia, aos empresários, e às sociedades civis latino-americanas.

\section{Referências bibliográficas}

AGLIETTA, Michel (1998), "Capitalism at the Turn of the Century: Regulation Theory and the Challenge of Social Change" New Left Review, n. 232 - November-December. p. 41 - 90.

AMSDEN, A. (1989), Asia's Next Giant: South Korea and Late Industrialization, New York: Oxford University Press. 
APPADURAI, Arjun (1990) "Disjuncture and Difference in the Global Cultural Economy." In Global Culture. p. 295-310. London. Sage Publications.

(1996), Modernity at Large: Cultural Dimensions of Globalization. Minneapolis: University of Minnesota Press.

ARCHIBUGI, Daniele (ed.) (2003). Debating Cosmopolitics. London: Verso.

BERGER, P. and LUCKMANN, T. (1967), The Social Construction of Reality. New York: Doubleday.

BLUMER, H. (1969), Symbolic Interactionism. Englewood Cliffs, NJ: Prentice-Hall.

BRAITHWAITE, John (2005), Regulatory Capitalism: How it Works, Ideas for Making it Work Better. Edward Elgar. Cheltenham, UK.

BRENNER, N., PECK, J., and THEODORE, N. (2010), "Variegated Neoliberalization: Geographies, Modalities \& Pathways". Global Networks. v.10, n.2.

BRESSER-PEREIRA, Luiz Carlos (2016), "Models of Developmental State". FGV - São Paulo School of Economics. WP n. 426, set. 16.

BULL, Hedley (2nd Ed.) (1995), The Anarchical Society: A Study of Order in World Politics. Houndmills, Macmillan.

CAMPBELL, J. (1988), "Institutional analysis and the role of ideas in political economy". Theory and Society, v. 27, n. 3, p. 377-409.

CHANG, Ha-Joon (2002), Kicking Away the Ladder. London: Anthem Press.

CALHOUN, Craig (2007), Nations Matter: Culture, History and Cosmopolitan Dream. London: Routledge.

CERNY, P. (2010), Rethinking World Politics: A Theory of Transnational Neopluralism. Oxford: Oxford University Press.

COASE, R.H. (1937), “The Nature of the Firm”, Economica v.4, n.16, p. 386-405.

CROUCH, Colin (2011), The Strange Non-Death of Neoliberalism. Cambridge. Polity Press. 
DRAKE, Paul (2006), "The Hegemony of US Economic Doctrines in Latin America” in E. Hersberg and F. Rosen (eds.) Latin America after Neoliberalism Turning the Tide in the 21st Century? New York: New Press.

EBENAU, Matthias, BRUFF, Ian., \& MAY, Christian (eds.) (2015), New Directions in Comparative Capitalisms Research - Critical \& Global Perspectives. Basingstoke. Palgrave Macmillan.

ESPING-ANDERSEN, Gøsta (1990), The Three Worlds of Welfare Capitalism. Princeton: Princeton University Press.

EVANS, Peter (1995), Embedded Autonomy: states and industrial transformation. Princeton, NJ: Princeton University Press.

(2007) "Los retos del "giro institucional”", em Instituciones y Desarrollo en la Era de la Globalización Neoliberal. p. 194. Publicaciones ILSA. Bogotá, Colombia.

GARY, Dymski and SILVANA de Paula (eds) (2005), Reimagining Growth: Institutions, Development, and Society, London and New York: Zed Books.

GIDDENS, Anthony (1971), Capitalism and Modern Social Theory. Cambridge: Cambridge University Press.

GILL, Stephen (2015), Critical Perspectives on the Crisis of Global Governance: Reimagining the Future. Basingstoke. Palgrave Macmillan.

HAGGARD, S. (2004), 'Institutions and Growth in East Asia', Studies in Comparative International Development. 38(4): 53-81.

HALL, Peter A. (ed.) (1989). The Political Power of Economic Ideas. Princeton: Princeton University Press.

HELD, David (1995), Democracy and the Global Order: From the Modern State to Cosmopolitan Governance. Cambridge: Polity Press.

HEWSON, M. and SINCLAIR, T. (1999), Approaches to Global Governance Theory. Albany, NY: State University of New York Press. 
HIRSCHMAN, Albert (1977), The Passions and the Interests: Political Arguments for Capitalism Before Its Triumph. Princeton, NJ: Princeton University Press.

HODGSON, Geoffrey M., Warren J. SAMUELS and Marc R. TOOL (eds) (1994), The Elgar Companion to Institutional and Evolutionary Economics, Aldershot: Edward Elgar.

JOHN, Peter (1988), Analysing public policy. London: Continuum.

JOHNSON, C. (1987) "Political institutions and Economic Performance: the GovernmentBusiness Relationship in Japan, South Korea, and Taiwan”, in C.D. Frederic (1987) (ed.) The Political Economy of New Asian Industrialism, Ithaca: Cornell University Press.

KEOHANE, Robert (1977), Power and Interdependence. World Politics in Transition. Boston: Little, Brown.

KINGSTONE, P. (2011), The Political Economy of Latin America. New York. Routledge.

LEFTWICH Adrian (1993), "Governance, Democracy and Development in the Third World". Third World Quarterly, v.14, p. 605-24.

(2008), "Developmental states, effective states and poverty reduction: The primacy of politics". UNRISD, Geneva.

MEYER, John W. (1999), "The Changing Cultural Content of the Nation-State: A World Society Perspective". In G. Steinmetz, Ed., State/Culture: State Formation after the Cultural Turn, Cornell University - p. 123-43.

MOUFFE, Chantal (2000), The Democratic Paradox. London, Verso.

NORTH, Douglass C. and ROBERT PAUL, Thomas (1973), The Rise of the Western World. Cambridge: Cambridge University Press.

PETRAS, James (2003), The New Development Politics: The Age of Empire Building and New Social Movements. London. Ashgate.

PIERRE, J. \& PETERS, G. P. (2000), Governance, Politics and the State. Basingstoke: Macmillan. 
POLANYI, Karl [1944] 2001. The Great Transformation: The Political and Economic Origins of Our Time. Boston, MA: Beacon Press.

RHODES, R. A. (1997), Understanding Governance: Policy Networks, Governance, Reflexivity and Accountability. Philadelhia, PA: Open University Press.

RIST, Gilbert (third edition) (2008), translated by Patrick Camiller. The History of Development: From Western Origins to Global Faith. London. Zed Books.

SASSEN, Saskia (2002), “The Repositioning of Citizenship: Emergent Subjects and Space for Politics”. Berkeley Journal of Sociology: A Critical Review v.46: p. 4-26.

SCHNEIDER, B. R. (2013), Hierarchical Capitalism in Latin America: Business, Labor, and the Challenges of Equitable Development. Cambridge: Cambridge University Press.

SEN, Amartya (1999), Development as Freedom. Oxford. Oxford University Press.

SIMON, Herbert (1983), Reason in Human Affairs. Oxford: Blackwell.

SOEDERBERG, S., G. MENZ and P. CERNY (eds.) (2005), Internalizing Globalization: The Rise of Neoliberalism and the Decline of National Varieties of Capitalism. Basingstoke. Palgrave Macmillan.

SPRINGER, S. (2015), “Postneoliberalism?” Review of Radical Political Economy, v. 47, p. 5-17.

STREECK, W. (2012), “How to Study Contemporary Capitalism?” European Journal of Sociology, v. 53:1, p. 1-28.

TAYLOR, P.J. (1996) "Embedded Statism and the Social Sciences: Opening Up to New Spaces." Environment and Planning A v. 28, p. 1917- 1995.

WILLIS, Katie (2005), Theories and Practices of Development. Routledge Perspectives on Development. London. Routledge.

WOO-CUMINGS, Meredith (ed.) (1999), The Developmental State. Ithaca: Cornell University Press. 


\title{
A América Latina e os limites do Estado desenvolvimentista na governança neoliberal global
}

Resumo

$\mathrm{O}$ artigo tem como objetivo analisar os efeitos das ideias hegemônicas e do regime de governança neoliberal global sobre a formulação das políticas de desenvolvimento latino-americanas, destacando o renovado interesse do debate político e acadêmico da região acerca do conceito de Estado desenvolvimentista. Debruça-se sobre debates e controvérsias analíticas acerca das relações entre estrutura e atores, entre as políticas domésticas e internacionais, assim como da (re)produção dos regimes de governança. $\mathrm{O}$ artigo destaca o contexto sistêmico (histórico) do processo de globalização neoliberal, dos regimes de regulação transnacionais (governança global), e de suas interfaces e possíveis influências para a emergência (ou não) de alternativas políticas de desenvolvimento (Estado desenvolvimentista).

Palavras-chave: Estado desenvolvimentista, governança neoliberal, estrutura político-epistêmica, giro político à direita.

\section{America Latina y los limites del Estado desarrolista en la gobernanza neoliberal global}

\section{Resumen}

El artículo pretende analizar los efectos de las ideas hegemónicas y neoliberales de gobernanza global en la formulación de políticas de desarrollo en América Latina, destacando el renovado interés en el debate político y académico en la región acerca del concepto del Estado desarrollista. Se centra en el análisis de debates y controversias sobre las relaciones entre la estructura y los actores, entre las políticas nacionales e internacionales, así como la (re)producción de regímenes de gobernanza. El artículo resalta el contexto sistêmico (historico) del proceso de globalización neoliberal, transnacional de los regímenes reglamentarios (gobernanza global), y sus interfaces y sus posibles influencias de la aparición (o no) de las políticas de desarrollo alternativo (Estado desarrollista).

Palabras clave: Estado desarrollista, gobernanza neoliberal, estructura político-epistemica, giro político hacia la derecha

\section{Latin America and the limits of developmental state in the global neoliberal governance}

\begin{abstract}
The article aims to analyse the effects of hegemonic ideas and the neoliberal global governance on the formulation of development policies in Latin America, foregrounding the renewed interest in the promotion of the concept of developmental state into the political and academic debate in the region. Focusing on analytical debates and controversies about the relationships between structure and actors, between domestic and international policies, as well as the (re)production of governance regimes. The article highlights the systemic context (history) of the neoliberal globalization process, transnational regulatory regimes (global governance), and their interfaces and possible influences for the emergence (or not) of alternative development policies (developmental state).
\end{abstract}

Keywords: Developmental state, neoliberal governance, political-epistemic structure, political turn to the right 